\title{
An Epidemiological study of health behavioral and protective factors among school going adolescents (aged 13-17 years) of Ahmedabad, Gujarat using the Global School- based Student Health Survey (GSHS) questionnaire.
}

\section{Donald S Christian ${ }^{1}$, Mansi M Patel ${ }^{2}$, Asha K Solanki ${ }^{3}$}

${ }^{1}$ Associate Professor, Department of Community Medicine, GCS Medical College, Ahmedabad; ${ }^{2}$ Assistant Professor, Department of Community Medicine, GCS Medical College, Ahmedabad, Gujarat; ${ }^{3}$ Resident, Department of Community Medicine, GCS Medical College, Ahmedabad, Gujarat

\begin{tabular}{|c|c|c|c|c|c|c|c|c|}
\hline Abstract & Introduction & Methodology & Results & Conclusion & References & Citation & \multicolumn{2}{|c|}{ Tables / Figures } \\
\hline \multicolumn{9}{|c|}{ Corresponding Author } \\
\hline \multicolumn{8}{|c|}{$\begin{array}{l}\text { Dr. Mansi M. Patel, 11/A, Vrundavan Colony, Nr. Gevar Complex, Dafnala Road, Shahibaug, Ahmedabad- } \\
\text { 380004, Gujarat. } \\
\text { E Mail ID: } \text { mansipatel10@gmail.com }\end{array}$} & 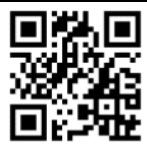 \\
\hline
\end{tabular}

\section{Citation}

Christian DS, Patel MM, Solanki AK. An Epidemiological study of health behavioral and protective factors among school going adolescents (aged 13-17 years) of Ahmedabad, Gujarat using the Global School-based Student Health Survey (GSHS) questionnaire. Indian J Comm Health. 2020;32(1):25 - 30.

Source of Funding: Nil Conflict of Interest: None declared

\section{Article Cycle}

Received: 03/12/2020; Revision: 15/12/2019; Accepted: 24/12/2019; Published: 31/03/2020 This work is licensed under a Creative Commons Attribution 4.0 International License.

\section{Abstract}

Background: Adolescence is considered as the next unsurpassed stage of life to childhood targeting for preventive and health promotional activities. Encouraging these activities firstly requires identification of high-risk behaviors and protective factors prevalent among such adolescents during current epidemiological transition period. Objective: To estimate the prevalence of various health behavioral and protective factors among school going adolescents of Ahmedabad. Methodology: A cross sectional study was conducted among 403 school going adolescents of rural field practice areas of a medical institute using GSHS self-administered questionnaire -Indian version. Almost all aspects of the questionnaire such as dietary behaviors, hygiene, mental health, physical activity, protective factors, tobacco use, violence \& unintentional injury, alcohol use and drug use were included in this study. Results: Out of a total of 403 students, $25.3 \%$ and $48.9 \%$ of students ate fruits and vegetables three or more times a day in past 30 days, respectively. About $41.2 \%$ of students drank carbonated drinks on two or more times per day. Majority (77.7\%) of the students brushed their teeth two times per day in past 30 days. Some $9.2 \%$ of students felt lonely in past 12 months and $8.4 \%$ of students had no close friends. Around $46.2 \%$ of students missed classes or school without permission in past 30 days. $30 \%$ of students remained physically active for all 7 days in last week. A few of students smoked cigarettes (2.5\%) and used any form of tobacco (7.9\%) on one or more days during past 30 days. The significant differences were found in many areas of risk behaviors as well as protective factors between boys and girls. Conclusion: Various unhealthy behaviors and protective factors were identified among school going adolescents from the present study. The difference was significant.

\section{Keywords}

Adolescent; Health behavior; Protective factors

\section{Introduction}

Adolescence is a developmental stage associated with many behavioral fluctuations and health risks behaviour (1) This includes aspects like, dietary behaviors, hygiene, mental health, physical activity, protective factors, tobacco use, violence $\&$ unintentional injury, alcohol use and drug use. This phase is so crucial for the foundations their adult lives. For instance, physical inactivity and low consumption of fruits and vegetables (FV) during adolescence may persist through adulthood, putting adolescents at risk of developing chronic diseases. Although studies from high-income countries have reported differences in FV consumption and physical activity (PA) between adolescent boys and girls, the data for low and middle income countries are lacking.(2) In addition, reduced mental health status in adolescents may lead to worse hygiene behaviors and an increased risk of infections. It is also to be noted here that the teachers, 
parents, healthcare workers, and other adults who observe suboptimal hygiene status in an adolescent should consider whether this indicates a mental health issue that requires clinical services.(3) On the other hands, exposure to violence and traumatic stressors among children is common and has both short- and long-term effects on multiple health behaviors (e.g. smoking, substance abuse, physical inactivity) and health outcomes (e.g. higher prevalence of heart, lung, and liver disease, diabetes, and depression). $(4,5)$ Moreover, such exposure appears to influence health behaviors and outcomes through a cumulative process.

The Global school-based student health survey- GSHS (6) is a collaborative surveillance tool designed to help countries measure and assess the behavioral risk factors and protective factors in those 10 key areas among young people aged 13 to 17 years. The GSHS is a relatively lowcost school-based survey which uses a self-administered questionnaire to obtain data on young people's health behavior and protective factors related to the leading causes of morbidity and mortality among children and adults worldwide. The 2007 India GSHS measured hygiene; dietary behaviors and overweight; physical activity; tobacco use; mental health and several protective factors. The 2007 India GSHS was a school-based survey of students in classes 8, 9, and 10 (7). Students scored low in eating breakfast, eating fruit, vegetables, and milk products. However, students scored moderately in hand and mouth hygiene. Students showed minimal incidences of physical attack and physical fight (7). Considering the relative lack of data related to these aspects in Indian adolescents (2), a study would be fruitful to throw light on situations of local adolescent students studying in the schools of field practice areas of the institute. It will enable us to develop priorities, establish programs, and advocate for resources for school health and youth health programs and policies.

\section{Aims \& Objectives}

1. To estimate the prevalence of various health behavioral and protective factors among school going adolescents of Ahmedabad.

2. To correlate the findings of health behavioral patterns with gender of these school going adolescents.

\section{Material \& Methods}

The study was conducted among school children who are enrolled in the schools within the field practice areas of rural health training center attached with the department of Community Medicine of a medical college of Ahmedabad city, Gujarat, which is located at Dabhoda village of Gujarat. A community based cross-sectional design was adopted for studying the health behavior and protective factors of school children. The school children aged 13-17 years were eligible to participate in the study. All the school children present in the school on the day of data collection were included in the study. Considering adolescent overall estimated healthy behavior of about $50 \%$ in the community, as local data are not available, the desired sample size came out to be 400 at $10 \%$ allowable error and at $5 \%$ precision. There are seven schools situated at Dabhoda vilage. Considering the age group of study participants, the schools having students from secondary standard were selected for survey. A list of registered school children from each class and standard was obtained from the selected schools. The equal numbers of students were selected from each standard through simple random sampling technique. Thus a total of 403 adolescent students were enrolled.

A pre-designed questionnaire "Global School-based Student Health Survey" (GSHS) developed by the World Health Organization for assessment of health behavior and protective factors among school children.(6) The GSHS questionnaire takes into consideration different modules related to respondents' demographics, Body Mass Index and dietary behaviors, hygiene-related behaviors, mental health issues, physical activity, protective factors, views on tobacco use and violence and unintentional injury. The updated GSHS questionnaire has been developed in 2006 for India and it is available in English as well as Hindi language. This questionnaire was translated in local language and then was back translated to maintain the content validity of the questions. The GSHS questionnaire (India) is a self-administered one. Therefore, the questionnaire was administered among school children for data collection. Institutional ethical approval was obtained before the start of the study. A pretest was carried out among 20 adolescents to know the feasibility of the questionnaire. If more than $20 \%$ of the data were missing from an assessment then the assessment was discarded. The permission as well as informed consent of the school principals was obtained for carrying out the study in their schools. The selfadministered GSHS questionnaire was distributed to the students for their responses following an initial session explaining the rationale of this survey and showing method to fill up the questionnaire. The absolute confidentiality was ensured to encourage the students to convey their correct views. The most of responses were recorded on five-point scale. The data entry was done in Microsoft excel and analysis was done by using SPSS software. Appropriate statistical tests were applied to get descriptive results in terms of percentages for health behaviors and protective factors as well as inferential statistics by using chi- square test for assessing relation between different health behaviors with independent variables.

\section{Results}

In the present study, 403 students were enrolled for the health behavioral survey. Mean age of students was 15.06 \pm 2.40 years. A total 238 (59\%) of students were boys 
while 165 (41\%) of them were girls. Among the total respondents, $51.1 \%$ of students were underweight while $9 \%$ of students were in pre-obese and obese categories. About $52.8 \%(n=19)$ of overweight students were trying to lose their weight while $56.8 \%(n=117)$ of underweight students were trying to maintain same weight or doing nothing for their weight. Out of all underweight students, $41.3 \%(n=85)$ perceived their weight as very underweight or slightly underweight while $47.2 \%(n=17)$ of overweight students perceived weight as slightly overweight. In relevance to dietary behavioural pattern, the more number of boys were eating fruits three or more times a day and vegetables five or more times a day in the past 30 days as compared to girls. These differences were found statistically significant. (Table 1 ) Majority of girls and boys were taught about benefits of eating healthy and eating fruits or vegetables in the last 12 months. The sex wise differences were found statistically significant in perceived education about benefits of healthy eating habits and eating more fruits-vegetables. (Table 1) About $7.9 \%(n=32)$ of the students ate fast food like samosa, noodles, dabeli in all 7 days. Only some $3.2 \%(n=13)$ of the students drank carbonated drinks like Coke, Pepsi, Limca, or Fanta etc. five or more times a day during past 30 days. The facilities for hand washing, facilities for clean drinking water and clean toilet facilities for girls and boys were available in the school. Only 21 (5\%) of the students had experienced toothache during past one year. The sex wise statistically significant differences were found for personal hygiene related parameters like washing hands before eating, after toilet, and washing hands using soap between boys and girls. (Table 2).

Almost $51.4 \%(n=207)$ of students never felt lonely in the past 12 months. About $37.5 \%(n=151)$ of students found difficulty in sleeping due to some worry during the past 12 months at the time of survey. Almost $81.9 \%(n=330)$ of them had three or more close friends. More than $50 \%$ of students ( $n=217$ and $n=218$ ) never found difficulty in concentrating and answering during past 12 months respectively. About $85.1 \%$ and $84.6 \%$ of students felt safe to reach to school and never experienced abuse by teachers during past 12 months. In the past 12 months, $60 \%$ of them never felt disturbed due to comments from peers, teachers, or family members. According to (Table $\underline{3}$ ), statistically significant differences were found between females and males for feeling loneliness and worried about something that they could not sleep at night on most of time or always during past 12 months. Out of all female students, $22.4 \%(n=37)$ felt so sad almost every day for two weeks or more in the past 12 months as compared to $13.4 \%(n=32)$ males and this difference was found statistically significant.

Protective factors were also identified in the present study (Table 4). More than $50 \%(n=217)$ of students never missed classes without permission during past 30 days. About $48.4 \%$ ( $n=195$ ) of students perceived that most of students in their school were always kind and helpful in the last 30 days. During past 30 days, 37\% $(n=149)$ of students' parents checked about completeness of their homework and activities done by students in spare time. Only $6 \%(n=24)$ of students' parents always understood their problem and worries during past 30 days. As mentioned in (Table 4), there were statistically significant differences were found in almost all protective factors issues among girls and boys except one issue that is the students perceived about most of the students in their school were never or rarely kind and helpful to them.

Out of total, $2.5 \%$ and $7.9 \%$ of students smoked cigarettes and used any form of tobacco on one or more days during past 30 days. For boys and girls, the greater statistically significant differences were found for smoking ( $4.2 \%$ vs. 0) and using any other form of tobacco (10.9\% vs. $3.6 \%$ ) in past 30 days at $p$ value of 0.007 and 0.008 respectively. About 181 (44.9\%) students reported that any of the parents use any form of tobacco. On the other hand, 32 (7.9\%) of students parents drink alcohol respectively. For passive smoking, $56.3 \%$ of students reported people smoked in their presence on one or more days during the past 7 days. $86.6 \%$ of them think about the smoking person who is either having lack of confidence or stupid. Only some of the students, $12.2 \% \quad(n=49)$ think that smoking cigarettes is not harmful to their health.

As per shown in (Table 5), the statistically significant difference was found in hours spent in sedentary activities by girls and boys. There was also statistically significant difference found in reaching school in more than 29 minutes by girls and boys. In this study, 112 (27.8\%) of students were remained physically inactive in last 7 days. Out of all, $18.1 \%(n=73)$ of students never attended physical education classes. Only some ( $n=146,36.2 \%)$ of students slept for 6 to 8 hours per day in a typical day. In about $27.5 \%(n=111)$ of the cases, students did not walk or ride bicycle to reach to school.

\section{Discussion}

In the present study, from a total of 403 students, the male and female proportions were $59.1 \%$ and $40.9 \%$, respectively. On the other hand, in a study by Siziya S. et al the respective proportions were $36.2 \%$ and $62.8 \%$ among the students of Swaziland.(8) This may be due to place of study and also the higher sample size $(\mathrm{N}=7341)$ in later study.

In the current study, boys (29.4\%) are more likely to have better food choices as far as eating fruits are concern than girls (19.4\%), which was statistically significant. However, there was no significant difference among both the sexes for the choice eating vegetables more often.(47.9\% vs $50.3 \%$ ) . In a study among Kuwaiti adolescent boys and girls, boys were more likely than girls to report healthy choices regarding both fruit (38.1\% vs. $33.2 \%)$ as well as vegetables (21.8\% vs. $16.7 \%) .(9)$. Overall, students scored moderately in eating fruits and vegetables (Table 2) and 
the score for mouth and hand hygiene was on a higher side (Table 3). A similar study conducted using GSHS at adolescent government school students of Jordan showed lower scores in eating fruits and vegetables and moderate scores in mouth and hand hygiene, which can be due to cultural differences among both the countries or due to higher sample size in the later. (10). The daily truth brushing for at least once a day was found in almost all of the students, while it was only $61.7 \%$ in Iranian students possibly due to mixture of social economic class in the later . (11)

The level of physical activity was also assessed in the present study. It showed that overall $30 \%$ of the students had optimum physical activity (at least 60 minutes per day) which was as comparable to a global study done among 49 low and middle income countries from 20042013 using GSHS tool where India showed a proportions of about $29.5 \%$.(12)

In the present study, for having missed classes more often, the proportions of males $(50.4 \%)$ was significantly higher than the proportions of females (40.0\%). Similar observation was found in the study by Siziya S. et al among Swaziland adolescents (8), while there was no significant difference for males and females in a similar study done by MacGillivary and Erickson in the United States. (13) The difference may be due to the fact that lunacy among boys is more acceptable in many developing countries. It was also important to know that in the present study, the parents are more never or rarely likely to understand the problems and worries of their children for both the sexes. However, there was a significant difference among males $(90.8 \%)$ and females $(70.3 \%)$ in the present study. It is an alarming aspect because parental support is very crucial for staying them away from anti-social activities, especially for males, as shown by Stanton in his study (14). In the present study, about $22.4 \%$ of the girls felt depressed and $16.4 \%$ of the girls felt loneliness, both the responses were significantly higher than male counterparts. Overall, the proportions of loneliness, anxiety related insomnia and depression were 9.2\%, 8.4\% and $17.1 \%$ respectively; while they were $8.6 \%, 7.8 \%$ and $25.5 \%$ respectively among 7904 middle school students of India quoted by Ranasinghe $S$ et at. So the rates were comparable for the present study. (15)

\section{Conclusion}

This study provides baseline information regarding unhealthy behaviors and other protective factors prevalent among school students of rural area. About half of underweight students were not doing anything about improving their weight and only $40 \%$ are truly aware about their status. Only quarters of the students have healthy eating practices in terms of frequency, and remained physically active for all seven days. In present study, girls are having lesser healthy food choices and more prevalent mental health issues but they have better hygienic practices. Boys are more prone to be injured, spent more hours in sedentary activities, and remained absent more in school than their counterpart. A few students ( 2.5 to $8 \%$ ) have tobacco addiction habits in past 30 days, which needs to be taken into consideration.

\section{Recommendation}

The health promotional activities as well as health education should be incorporated in the schooling life. The associations or support group must be developed to encourage the parent to become implicated in their children's life. The students must be promoted to articulate their feelings and endow with exposure to conflict management as well as meditation workouts. Parent-teacher interactions should not remain limited for younger children only. The reduction in unhealthy risk behaviors among rural adolescent might be attained by planning of focused formal or informal life skill education through school and other social institutions and mass media. An integrated action strategy involving various stakeholders (decision makers, community leaders, including teachers, parents, and adolescents) should be undertaken for prevention and control of health risk behaviors among adolescents.

\section{Limitation of the study}

The study was conducted among school going students only, so the results are dependent upon the school enrollment.

\section{Relevance of the study}

The study will enable the stakeholders like teachers, parents, healthcare workers and institutions to develop priorities, establish and take part in health programs, and advocate for resources for school health and youth health.

\section{Authors Contribution}

All the authors have contributed significantly for the designing the study, implementing it, collecting data and analyzing data as well as preparing the final document.

\section{Acknowledgement}

The authors would like to acknowledge the help by the school authorities as well as the Medical Social workers of the department of Community Medicine.

\section{References}

1. Al-Sagarat AY, Al Kalaldeh MT., Prevalence of Health-risk Behaviors among Government Schools' Students in Jordan. Iran J Public Health. 2017 Dec;46(12):1669-1678.

2. Darfour-Oduro SA, Buchner DM, Andrade JE, Grigsby-Toussaint DS., A comparative study of fruit and vegetable consumption and physical activity among adolescents in 49 Low-and-Middle-Income Countries, Sci Rep. 2018 Jan 26;8(1):1623. doi: 10.1038/s41598018-19956-0.,

3. Ranasinghe $\mathrm{S}$, Ramesh S, Jacobsen $\mathrm{KH}$.; Hygiene and mental health among middle school students in India and 11 other countries.; J Infect Public Health. 2016 Jul-Aug;9(4):429-35. doi: 10.1016/j.jiph.2015.11.007.

4. Centers for Disease Control and Prevention. Adverse childhood experiences study. Publications on major findings by health 
INDIAN JOURNAL OF COMMUNITY HEALTH / VOL 32 / ISSUE NO 01 / JAN - MAR 2020 outcomes. Atlanta, GA: CDC; 2009. Available from: www.cdc.gov/nccdphp/ACE/outcomes.htm

5. Chartier MJ, Walker JR, Naimark B. Childhood abuse, adult health, and health care utilization: results from a representative community sample. Am J Epidemiol 2007;165: 1031-8. PMID:17309899 doi:10.1093/aje/kwk113.

6. World Health Organization, Global School-based Student Health survey (GSHS) -Non-communicable diseases and their risk factors, from https://www.who.int/ncds/surveillance/gshs/en/ last accessed on November 04, 2018.

7. Global School-based Student Health Survey, India (CBSE) 2007 Fact Sheet, accessed from http://www.who.int/ncds/surveillance/gshs/2007 India_CBSE fa ct sheet.pdf on November 03, 2018.

8. Siziya S, Muula A S \& Rudatsikira E, Prevalence and correlates of truancy among adolescents in Swaziland: findings from the Global School-Based Health Survey; Child and Adolescent Psychiatry and Mental Health, 2007,1:15 https://doi.org/10.1186/1753-2000-115.

9. Badr HE, Lakha SF\& Pennefather P, Differences in physical activity, eating habits and risk of obesity among Kuwaiti adolescent boys and girls: a population-based study, Int J Adolesc Med Health. 2017 Jun 17. pii: /j/ijamh.ahead-of-print/ijamh-2016-0138/ijamh-20160138.xml. doi: 10.1515/ijamh-2016-0138.

10. Al-Sagarat AY, Al Kalaldeh MT, Prevalence of Health-risk Behaviors among Government Schools' Students in Jordan; Iran J Public Health. 2017 Dec;46(12):1669-1678.
[An Epidemiological study] | Christian DS et al

11 Qorbani M, Kelishadi R, Djalalinia S, Motlagh ME, Kasaeian A, Ardalan G, Shafiee G, Safari O, Heshmat R, BaradaranMahdavi S Regional disparity in hygienic behaviors of Iranian children and adolescents: The CASPIAN-IV study; Med J Islam Repub Iran. 2016 Oct 18;30:431.

12. Darfour-Oduro SA, Buchner DM, Andrade JE, Grigsby-Toussaint DS, A comparative study of fruit and vegetable consumption and physical activity among adolescents in 49 Low-and-Middle-Income Countries; Sci Rep. 2018 Jan 26;8(1):1623. doi: 10.1038/s41598018-19956-0.

13. MacGillivary H, Erickson G: Truancy in Denver: Prevalence, effects and interventions. 2006, National Centre for School Engagement, Denver, Colorado, Accessed 15 May 2007. http://www.schoolengagement.org/TruancypreventionRegistry/A dmin/Resources/Resources/108.pdf ]Google Scholar .]

14. Stanton B, Cole M, Galbraith J, Li X, Peddleton S, Cottrel L, Marshall $S$, Wu Y, Kaljee L: Randomized trial of a parent intervention: parents can make a difference in long-term adolescent risk behaviors, perceptions, and knowledge. Arch Pediatr Adolesc Med. 2004, 158 947-55. 10.1001/archpedi.158.10.947.

15. Ranasinghe $\mathrm{S}$, Ramesh $\mathrm{S}$, Jacobsen $\mathrm{KH}$; Hygiene and mental health among middle school students in India and 11 other countries, J Infect Public Health. 2016 Jul-Aug;9(4):429-35. doi: 10.1016/j.jiph.2015.11.007. Epub 2015 Dec 3.

\section{Tables}

TABLE 1 DISTRIBUTION OF DIETARY BEHAVIORAL PATTERN AMONG PARTICIPANTS ( $=403)$

\begin{tabular}{|c|c|c|c|c|}
\hline Variables & $\begin{array}{l}\text { Female } \\
(n=165)\end{array}$ & $\begin{array}{l}\text { Male } \\
(n=238)\end{array}$ & $\begin{array}{l}\text { Total } \\
(\mathrm{n}=403)\end{array}$ & p value \\
\hline Went hungry most of the time or always during the past 30 days & $5(3 \%)$ & $9(3.8 \%)$ & $14(3.5 \%)$ & 0.787 \\
\hline Usually ate fruit on three or more times per day during the past 30 days & $32(19.4 \%)$ & $70(29.4 \%)$ & $102(25.3 \%)$ & $0.027^{*}$ \\
\hline Usually ate vegetables on three or more times per day during the past 30 days & $83(50.3 \%)$ & $114(47.9 \%)$ & $197(48.9 \%)$ & 0.685 \\
\hline Ate fruits five or more times per day during the past 30 days & $2(1.2 \%)$ & $8(3.4 \%)$ & $10(2.5 \%)$ & 0.209 \\
\hline Ate vegetables five or more times per day during the past 30 days & $0(0 \%)$ & $13(5.5 \%)$ & $13(3.2 \%)$ & $0.005 \#$ \\
\hline $\begin{array}{l}\text { Usually drank carbonated soft drinks on two or more times per day during the } \\
\text { past } 30 \text { days }\end{array}$ & $70(42.4 \%)$ & $96(40.3 \%)$ & $166(41.2 \%)$ & 0.682 \\
\hline Ate at fast food on three or more of the past seven days & $58(35.2 \%)$ & $73(30.7 \%)$ & $131(32.5 \%)$ & 0.387 \\
\hline Benefits of healthy eating was taught in last 12 months & $160(97 \%)$ & $214(89.9 \%)$ & $374(92.8 \%)$ & $0.007^{*}$ \\
\hline Benefits of eating more fruits and vegetables was taught in last 12 months & $\begin{array}{l}155 \\
(93.9 \%)\end{array}$ & $\begin{array}{l}201 \\
(84.5 / \%)\end{array}$ & $356(88.3 \%)$ & 0.004 \\
\hline
\end{tabular}

*Statistically significant at $\mathrm{p}$ value of $<0.05$ \# Fisher's exact test value.

TABLE 2 DISTRIBUTION OF PERSONAL HYGIENE BEHAVIOR AMONG PARTICIPANTS (N=403)

\begin{tabular}{|c|c|c|c|c|}
\hline Variables & $\begin{array}{l}\text { Female } \\
\text { ( } n=165)\end{array}$ & $\begin{array}{l}\text { Male } \\
(n=238)\end{array}$ & $\begin{array}{l}\text { Total } \\
(n=403)\end{array}$ & $p$ value \\
\hline Cleaned or brushed their teeth less than 1 time per day during the past 30 days & $1(0.6 \%)$ & $6(2.5 \%)$ & $7(1.7 \%)$ & 0.248 \\
\hline Never or rarely washed their hands before eating during the past 30 days & $11(6.7 \%)$ & $35(14.7 \%)$ & $46(11.4 \%)$ & $0.016^{*}$ \\
\hline $\begin{array}{l}\text { Never or rarely washed their hands after using the toilet or latrine during the } \\
\text { past 30days }\end{array}$ & $6(3.6 \%)$ & $21(8.8 \%)$ & $27(6.7 \%)$ & $0.041^{*}$ \\
\hline Never or rarely used soap when washing their hands during the past 30 days & $16(9.7 \%)$ & $57(23.9 \%)$ & $73(18.1 \%)$ & $0.000 *$ \\
\hline
\end{tabular}

*Statistically significant at $p$ value of $<0.05$

TABLE 3 DISTRIBUTION OF ISSUES REGARDING MENTAL HEALTH, VIOLENCE AND UNINTENTIONAL INJURY AMONG PARTICIPANTS ( $\mathrm{N}=403)$

\begin{tabular}{|c|c|c|c|c|}
\hline Variables & $\begin{array}{l}\text { Female } \\
(n=165)\end{array}$ & $\begin{array}{l}\text { Male } \\
(n=238)\end{array}$ & $\begin{array}{l}\text { Total } \\
(n=403)\end{array}$ & $p$ value \\
\hline Most of the time or always felt lonely during the past 12 months & $27(16.4 \%)$ & $10(4.2 \%)$ & $37(9.2 \%)$ & $0.000^{*}$ \\
\hline $\begin{array}{l}\text { Most of the time or always felt so worried about something that they could } \\
\text { not sleep at night during the past } 12 \text { months }\end{array}$ & $15(9.1 \%)$ & $19(8 \%)$ & $34(8.4 \%)$ & $0.000 *$ \\
\hline $\begin{array}{l}\text { Felt so sad or hopeless almost every day for two weeks or more in a row } \\
\text { that they stopped doing their usual activities during the past } 12 \text { months }\end{array}$ & $37(22.4 \%)$ & $32(13.4 \%)$ & $69(17.1 \%)$ & $0.018^{*}$ \\
\hline
\end{tabular}


Have no close friends

[An Epidemiological study] | Christian DS et al

Most of the time or always felt hard time answering questions or writing

on the blackboard in front of your class

Most of the time or always felt disturbed due to the comments from your

peers, family members, or teachers

Most of the time or always felt hard time staying focused on your

homework or other things you had to do

Abused by teacher on one or more time in the last 12 months

Felt unsafe to reach the school on one or more time in the last 12 months

Got injured in the past 12 months

\begin{tabular}{l|l|l}
$16(6.7 \%)$ & $34(8.4 \%)$ & 0.148
\end{tabular}

$18(10.9 \%)$

$16(6.7 \%)$

$34(8.4 \%)$

0.148

$12(7.3 \%)$

$27(11.3 \%)$

$39(9.7 \%)$

0.230

*Statistically significant at $p$ value of $<0.05$

\section{TABLE 4 DISTRIBUTION OF PROTECTIVE FACTOR ISSUES AMONG PARTICIPANTS (N=403)}

\begin{tabular}{|c|c|c|c|c|}
\hline Variables & $\begin{array}{l}\text { Female } \\
(n=165)\end{array}$ & $\begin{array}{l}\text { Male } \\
\text { (n=238) }\end{array}$ & $\begin{array}{l}\text { Total } \\
(n=403)\end{array}$ & p value \\
\hline Missed classes or school without permission on one or more of the past 30 days & $66(40 \%)$ & $\begin{array}{l}120 \\
(50.4 \%)\end{array}$ & $\begin{array}{l}186 \\
(46.2 \%)\end{array}$ & $0.039 *$ \\
\hline $\begin{array}{l}\text { Reported that most of the students in their school were kind and helpful never or } \\
\text { rarely during the past } 30 \text { days }\end{array}$ & $\begin{array}{l}81 \\
(49.1 \%)\end{array}$ & $\begin{array}{l}101 \\
(42.4 \%)\end{array}$ & $\begin{array}{l}182 \\
(45.2 \%)\end{array}$ & 0.187 \\
\hline $\begin{array}{l}\text { Students whose parents or guardians never or rarely checked to see if their } \\
\text { homework was done during the past } 30 \text { days }\end{array}$ & $\begin{array}{l}80 \\
(48.5 \%)\end{array}$ & $60(25.2 \%)$ & $\begin{array}{l}140 \\
(34.7 \%)\end{array}$ & $0.001 *$ \\
\hline $\begin{array}{l}\text { Student whose parents or guardians never or rarely understood their problems and } \\
\text { worries during the past } 30 \text { days }\end{array}$ & $\begin{array}{l}116 \\
(70.3 \%)\end{array}$ & $\begin{array}{l}216 \\
(90.8 \%)\end{array}$ & $\begin{array}{l}332 \\
(82.4 \%)\end{array}$ & $0.002 *$ \\
\hline $\begin{array}{l}\text { Students whose parents or guardians never or rarely knew what they were doing } \\
\text { with their free time during the past } 30 \text { days }\end{array}$ & $\begin{array}{l}65 \\
(39.4 \%)\end{array}$ & $67(28.1 \%)$ & $\begin{array}{l}132 \\
(32.7 \%)\end{array}$ & $0.024 *$ \\
\hline
\end{tabular}

\section{TABLE 5 DISTRIBUTION OF PHYSICAL ACTIVITY LEVEL AMONG PARTICIPANTS (N=403)}

\begin{tabular}{|c|c|c|c|c|}
\hline Variables & $\begin{array}{l}\text { Female } \\
(n=165)\end{array}$ & $\begin{array}{l}\text { Male } \\
(n=238)\end{array}$ & $\begin{array}{l}\text { Total } \\
(\mathrm{N}=403)\end{array}$ & p value \\
\hline $\begin{array}{l}\text { Physically active for a total of at least } 60 \text { minutes per day on all } 7 \text { days during the past } \\
\text { seven days }\end{array}$ & $53(32.1 \%)$ & $\begin{array}{l}68 \\
(28.6 \%)\end{array}$ & $\begin{array}{l}121 \\
(30 \%)\end{array}$ & 0.507 \\
\hline $\begin{array}{l}\text { Physically active seven days for a total of at least } 60 \text { minutes per day during a typical } \\
\text { or usual week }\end{array}$ & $43(26.1 \%)$ & $\begin{array}{l}55 \\
(23.1 \%)\end{array}$ & $\begin{array}{l}98 \\
(24.3 \%)\end{array}$ & 0.555 \\
\hline $\begin{array}{l}\text { Spent three or more hours per day during a typical or usual day sitting and watching } \\
\text { television or doing other sitting activities, such as reading a novel }\end{array}$ & $21(12.7 \%)$ & $\begin{array}{l}68 \\
(28.6 \%)\end{array}$ & $89(22.1)$ & $0.000^{*}$ \\
\hline Did not walk or bicycle to and from school during the past seven days & $42(25.5 \%)$ & $69(29 \%)$ & $\begin{array}{l}111 \\
(27.5 \%)\end{array}$ & 0.434 \\
\hline $\begin{array}{l}\text { Usually took more than } 29 \text { minutes each day to get to and from school during the past } \\
\text { seven days }\end{array}$ & $16(9.6 \%)$ & $\begin{array}{l}37 \\
(15.5 \%)\end{array}$ & $\begin{array}{l}53 \\
(13.1 \%)\end{array}$ & $0.026^{*}$ \\
\hline Went to physical education class 4 or more days each week during the school year & $91(55.2 \%)$ & $\begin{array}{l}129 \\
(54.2 \%)\end{array}$ & $\begin{array}{l}220 \\
(54.6 \%)\end{array}$ & 0.851 \\
\hline
\end{tabular}

*Statistically significant at $p$ value of $<0.05$ 